\title{
Eco-driving: behavioural pattern change in Polish passenger vehicle drivers
}

\author{
Piotr Oskar Czechowski ${ }^{1 *}$, Aneta Oniszczuk-Jastrząbek², and Tomasz Czuba² \\ ${ }^{1}$ Gdynia Maritime University, Faculty of Entrepreneurship and Quality Science, Gdynia, Poland \\ ${ }^{2}$ Gdańsk University, Faculty of Economics, Sopot, Poland
}

\begin{abstract}
In Poland, as in the rest of Europe, air quality depends primarily on emissions from municipal, domestic and road transport sources. The problems of appropriate air quality are especially important within urban areas due to numerous sources of emissions being concentrated in relatively small spaces in both large cities and small/medium-sized towns. Due to the steadily increasing share of urban population in the overall number of population, the issue of providing clean air will over the years become a more significant problem for human health, and therefore a stronger incentive to intensify research. The key challenge faced by a modern society is, therefore, to limit harmful substance emissions in order to minimise the contribution of transport to pollution and health hazards. Increasingly stringent emission standards are being imposed on car manufacturers; on the other hand, scant regard is paid to the issue of drivers, i.e. how they can help reduce emissions and protect their life and health by applying eco-driving rules.
\end{abstract}

\section{Introduction}

The health effects of the impact of pollution on the humans are sometimes difficult to estimate, because they depend on the substance and its concentration, as well as the time of exposure. According to WHO, 1.3 million city-dwellers die prematurely around the world each year as a result of air pollution [1]. In Europe (according to EEA data [2]), the death toll includes 350 thousand premature deaths due to exposure to $\mathrm{PM}_{2,5}$ as well as 20 thousand premature deaths due to exposure to high concentrations of $\mathrm{O}_{3}$ [3]. WHO data [4] also shows that exposure to particulate matter is a worldwide cause of $8 \%$ deaths due to lung cancer, $5 \%$ deaths due to cardiovascular disease, $3 \%$ deaths due to respiratory infections. WHO also demonstrates [5] that an increased morbidity / mortality risk due to respiratory diseases is associated with exposure to $\mathrm{NO}_{2}$, including at concentrations below the limit values.

At a time when human activity is having more of a negative environmental impact, contributing to increased carbon dioxide emissions into the atmosphere, and fuel prices are rising, the knowledge and practice of eco-driving techniques are soon bound to become an important life skill.

This article surveys primary research based on interviews with Polish drivers, providing the motivation for the author's own statistical models and reflections on the subject. The research was undertaken with the basic aim of examining eco-driving awareness and

\footnotetext{
* Corresponding author: e-mail: oskar@am.gdynia.pl
} 
behaviour. To achieve the aim of stepping up measures to promote eco-driving, however, it is necessary to explain what eco-driving involves. The research has provided a way to evaluate the awareness level of eco-driving and identify measures which further responsible driving behaviour in Polish drivers, while also recognizing factors which contribute to fuel savings in city driving. The research involved seeking information on average fuel consumption in city and out-of-city conditions when obeying and ignoring eco-driving rules. The models proposed compare fuel consumption in eco-driving and non-eco-driving situations.

The issues which the models seek to address include:

1. Empirical distributions of selected variables.

2. Factors contributing to lower fuel consumption in city driving.

3. Eco-driving awareness, including driver profiles of those who recognize and apply ecodriving techniques.

\section{Review of the literature}

Air pollution and noise levels are becoming more and more of a problem every year. Air pollution contributes significantly to health issues, leading to numerous respiratory and circulatory diseases. Having regard to health and environment protection as a whole, it is especially important to combat emissions. Industrial operations and transportation are responsible for dust and toxic gas emissions which combined with humid and windless conditions result in the formation of an unnatural weather phenomenon - smog. The effects of smog are most visible in large city areas, causing urban decay and health problems, as growing numbers of people are struggling with allergic reactions, asthma and respiratory failure [6].

According to WHO, inhaling harmful particles from polluted air is the cause of 2 million deaths every year. Scientists agree that implementing solutions designed to limit poisonous gas emissions would reduce the number of premature deaths by up to $2 / 3$. PM10 particles can make their way into the lungs and bloodstream, resulting in cardiac failure, lung cancer, asthma and acute respiratory infections. These are the findings of a WHO report based on research conducted by that organization. Pollution comes mainly from coalburning power plants and vehicle engines [7] .

A review of $\mathrm{CO}_{2}$ emissions figures by sector and projections of changes in emissions expected up until 2030 confirms that the decarbonisation of the transport industry requires the implementation of a series of initiatives [8] based on innovative technologies, organizational improvements and behavioural adjustments. Despite technological advancement, there is a continuing (and growing) source of climate-changing $\mathrm{CO}_{2}$ emissions in the form of high traffic flow in city areas and urban driving style characterized by frequent stopping and moving off.

One of the initiatives to limit $\mathrm{CO}_{2}$ emissions is eco-driving. Eco-driving is basically a smooth and controlled method of driving a car. The following essential driving tips are offered: plan journeys ahead, anticipate traffic flow, move into the highest possible gear while keeping a constant speed, brake gently by gearing down, turn off the engine when stopped for longer than a minute, avoid engine pre-heating (including in winter), maintain correct tyre pressure, limit air conditioning usage to a reasonable minimum $[9,10]$. The relations between individual items on the list are widely discussed by Andoa, Nishihori [11], Andrieu, Saint Pierre [12]. To achieve its aim, the article examines driving awareness and behaviour.

Research from pilot studies shows that eco-driving reduces average fuel consumption by $10 \%$ per kilometre [13]. Also, this manner of driving reduces $\mathrm{CO}_{2}$ emissions by $6-10 \%$ [13] and fuel consumption in buses by $2 \%$ in the 12 months following training [14] $4.35 \%$ 
in the two-month follow-up period [15]. The mean change in fuel consumption for all drivers in the study after their eco-driving course was a reduction of $5.8 \%$, but with large differences between individuals [16].

Various factors may contribute to improving driver behaviour and eco-driving awareness. Research conducted by Boriboonsomsin, et.al. shows that $40 \%$ of respondents have changed their driving style in reaction to a rise in fuel prices. Other factors may include, e.g. vehicle weight, road quality, weather conditions, road congestion or the need for reducing carbon dioxide emissions [10].

According to Jack N. Barkenhaus, eco-driving brings substantial benefits to individuals (lower costs and better personal safety) and society (reduced $\mathrm{CO}_{2}$ emission, lower oil imports, less conventional emissions and lower death rate) $[17,18,19,20]$. The authors of the article decided to investigate which factor - economic or ecological - contributes more to Polish drivers following eco-driving rules.

\section{Methodology}

The nationwide study (using the direct interview method (PAPI)) examined how drivers / passenger vehicle owners employ the rules of eco-drive and how this affects their health. The research was carried out in the period between 12 November 2015 and 30 November 2015 on a random sample of 1000 drivers / passenger vehicle owners throughout the country. The attitude to eco-driving was one of the points of this study that focused on driver behaviour and preference in terms of patterns of petrol station visits.

The aim of the study was to assess driver awareness of eco-driving techniques and verify their use in practice. The separate point was to identify factors contributing to reducing fuel consumption. The bulk of research work was aimed at proving that transport pollution levels could be reduced dramatically through individual action, leading to significant reductions of emissions globally.

In order to verify the hypotheses, the selected models were used, depending on the measurement scales of researched empirical stochastic and exploratory variables and assumptions. Among the key models, the following should be mentioned: simple models of the ANOVA family, multidimensional principal component (PCA) and correspondence analysis (CA) models, as well as advanced generalised regression models (GRM). The obtained results fully addressed all of the research goals, while the cognitive value gained in the process proved to be useful in a practical dimension. It shows how well the rules of eco-driving are known and applied in practice. The awareness of principles of eco-driving is at a low level in Poland and undertaking educational action is the only way to bring the desired (including health-related) effects for the general public. It is especially important in the context of constantly growing number of cars and risks related to air pollution. High awareness of eco-driving among drivers / passenger vehicle owner will have an advantageous impact on health protection and natural environment.

A basic research problem is to answer questions in which both dependent and independent variables are measured on weak, i.e. nominal and ordinal, scales. This is due to the fact that a classic regressive model cannot be adopted here.

An alternative solution is to use linear log models, and specifically, a logistic regression model. It assumes that a dependent variable is a dichotomous variable, while independent variables can be measured on any measurement scale.

Further on, a model of factors contributing to eco-driving awareness will be used as an example to explain the model estimation results. The knowledge of eco-driving is a dichotomous dependent variable, in which a negative answer is coded as " 0 " and a positive one as "1." Independent variables relating to the knowledge of eco-driving are measured on various measurement scales, such as "age" (ordinal scale), "gender" (nominal scale). 
A multiple regression model is the most appropriate quantitative analysis method to determine which variables under consideration are factors with a relevant impact on the knowledge of eco-driving. A standard solution, such as, for example, multi-dimensional regression would be insufficient to examine this type of cause-and-effect relationship, as different scales have been used to evaluate variables. It has been assumed that a logistic regression model will allow identifying relevant factors. The identification in this particular case is limited to seeking to establish a regression-like connection between the occurrence probability of a given variant (contact / no contact) with a group of independent variables, such as respondent answers and other factors, e.g. gender.

\section{Factors contributing to eco-driving awareness}

\subsection{Analysis of variance (ANOVA)}

The aim of analysis of variance (ANOVA) is to analyse differences between group means, both within specific groups and across groups in populations from which samples were drawn.

Generally speaking, it is a technique of analysing variables (experiment results, observations) which depend on one or several co-occurring factors. Here, unlike in exploratory methods, these factors are known. The most frequently considered factors in this research include gender, university, place of origin, place of residence and others (these are sometimes referred to as grouping, classifying or manipulating factors). Each factor has a number of variants, such as male / female gender, six tertiary education centres in the Tricity area, three variants for place of origin (places with population ranges from up 5 thousand, from 5 to 50 thousand, and over 50 thousand) and four variants for place of residence while in college (dormitory, rented quarters, family home, home-owner). ANOVA allows verifying whether the factors under analysis have an impact on the observed variables.

A variable analysed in this way is known as a dependent variable and must be at least interval-scaled, e.g. respondent age (in years). A single-factor analysis of variance test examines factor impact on the outcomes of a relevant feature. The analysis of variance test is presented in Table 1.

Table 1. Table of analysis of variance (ANOVA)

\begin{tabular}{|c|c|c|c|c|}
\hline Source of variability & Sum of squares & $\begin{array}{c}\text { Degrees } \\
\text { of freedom }\end{array}$ & Variance & F-Test \\
\hline Across populations (groups) & $\sum_{i=1}^{k}\left(\bar{x}_{i}-\bar{x}\right)^{2} n_{i}$ & $\mathrm{k}-1$ & $\hat{S}_{1}^{2}$ & $F=\frac{\hat{S}_{1}^{2}}{\hat{S}_{2}^{2}}$ \\
\hline Within groups (random effect) & $\sum_{i=1}^{k} \sum_{j=1}^{n_{i}}\left(x_{i j}-\bar{x}_{i}\right)^{2}$ & $\mathrm{n}-\mathrm{k}$ & $\hat{S}_{2}^{2}$ & \\
\hline
\end{tabular}

Source: Author's own research

The $F$-statistic value is compared with critical value $F \alpha$, k-1,n-k taken from F-Snedecor distribution tables for specific relevance level $\alpha$ and specific number of degrees of freedom $\mathrm{k}-1 \mathrm{i} \mathrm{n}-\mathrm{k}$. If $\mathrm{F} \geq \mathrm{F} \alpha, \mathrm{k}-1, \mathrm{n}-\mathrm{k}$, then $\mathrm{H}_{0}$ hypothesis on the equality of means in the population should be rejected. On the other hand, for $\mathrm{F}<\mathrm{F} \alpha, \mathrm{k}-1, \mathrm{n}-\mathrm{k}$, there is no basis for rejecting hypothesis $\mathrm{H}_{0}$. Rejecting a zero hypothesis constitutes proof of a relevant impact on the populations under survey. Otherwise, all the populations could be considered equal in terms of feature values obtained, which means that the dependent variable is not impacted by the factor. 


\subsection{Kruskal-Wallis Test}

The classic ANOVA is not applicable to situations where the variance equality condition is not satisfied. An alternative to one-way ANOVA is provided by non-parametric KruskalWallis test (KW ANOVA).

This test assumes that a variable under consideration is a continuous variable which has at least been interval-scaled. The hypothesis tested here is that samples have been drawn from a population following the same distribution or from distributions having the same median. The method of interpretation for this test is the same as in a single-factor parametric ANOVA except here it is based on ranks, not on means.

$$
H=\frac{12}{n(n+1)} \sum_{i=1}^{k} \frac{T_{i}^{2}}{n_{i}}-3(n+1)
$$

where: $n-$ total size $=\sum_{i=1}^{k} n_{i}, n_{i}-$ group size, $T_{i}-$ sum of ranks for a given group, $k-$ number of groups / $n$ - is the total number of observations across all groups $=\sum_{i=1}^{k} n_{i}, n_{i}-i$ s the number of observations in group $i, T_{i}$ - is the sum of rank (among all observations) of observation from group $i, k$-number of group

\section{Factors contributing to reducing fuel consumption in city driving - research results}

\subsection{Relationship between eco-driving awareness and reduced fuel consumption in city driving}

The research question was to establish the relationship of eco-driving awareness and reduced fuel consumption in city driving (Table 2).

Because of failure to satisfy the condition of variance homogeneity in a classic ANOVA model, an alternative KW ANOVA (Kruskal-Wallis) model has been applied, as presented in Table 2.

Table 2. Relationship between eco-driving awareness and reduced fuel consumption in city driving

\begin{tabular}{|c|c|c|c|}
\hline \multirow[t]{2}{*}{ Eco-driving - Have you heard...? } & $\begin{array}{c}\text { DifferencesM } \\
\left(4 \_3-4 \_1\right)\end{array}$ & $\begin{array}{c}\text { DifferencesM } \\
\left(4 \_3-4 \_1\right)\end{array}$ & $\begin{array}{c}\text { DifferencesM } \\
\left(4 \_3-4 \_1\right)\end{array}$ \\
\hline & Mean & Valid & Standard deviation \\
\hline I have never met with this concept & -0.66319 & 47 & 1.445497 \\
\hline $\begin{array}{l}\text { I have met with this concept, but I do } \\
\text { not know exactly what it means }\end{array}$ & -0.86642 & 134 & 1.301066 \\
\hline $\begin{array}{l}\text { I have met with this concept, and I } \\
\text { know exactly what it means }\end{array}$ & -0.87823 & 271 & 0.888573 \\
\hline I do not know / hard to say & -2.25000 & 6 & 3.342903 \\
\hline Total & -0.87068 & 458 & 1.149414 \\
\hline
\end{tabular}

Source: Author's own research

Both models point to a significant influence of eco-driving awareness on fuel consumption, but excessive dispersion in the distribution of respondents declaring uncertainty prevents a clear-cut answer. It is necessary to develop more detailed models taking account of more factors (GRM).

\subsection{Identification of factors contributing to reducing fuel consumption}


A GRM model has been applied to identify factors contributing to reducing fuel consumption. Five relevant variables have been identified. The strongest factors turned out to be age, eco-driving awareness and gender, as presented synthetically in the Pareto graph (Fig. 1.) using t-statistic value modules for each factor.

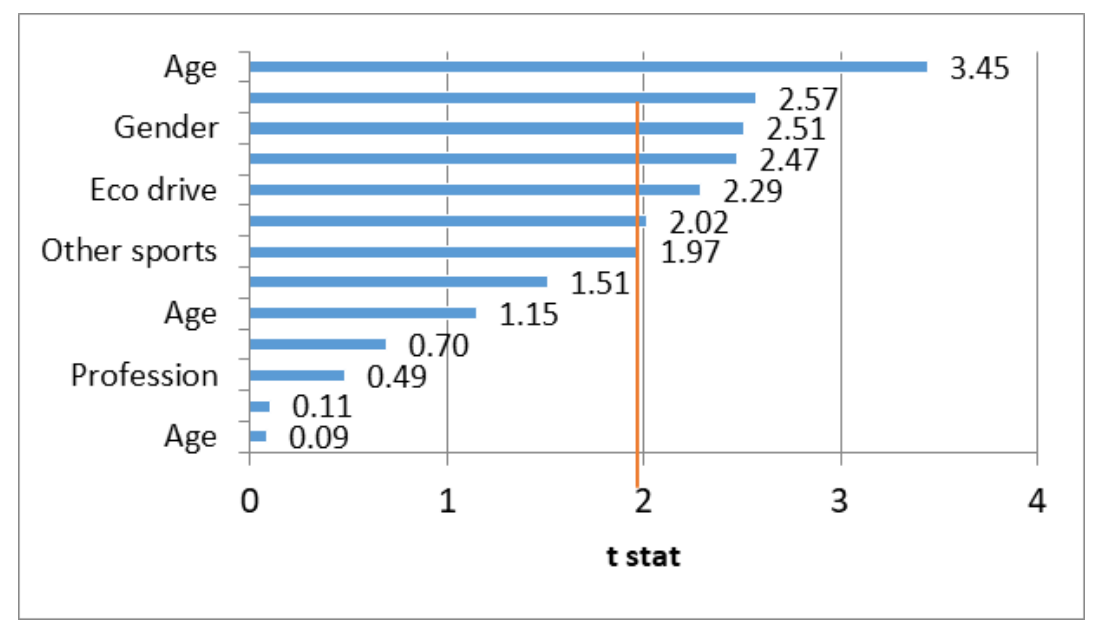

Fig. 1. Pareto-model of fuel consumption factors

Source: Author's own research

Individual factor values have varying impacts on fuel consumption savings. Largest fuel savings have been observed in the youngest age group under 25 but with the highest degree of statistical dispersion, which points to a strong heterogeneity of that group. This may also suggest that this age group is need of saving money. The asymmetry is strongly left-skewed (alpha3=-2.13; Table 3), suggesting a majority of respondents, whose fuel consumption saving is above the average value in the distribution, and who therefore do not drive economically. The age group over 60 is the only one to display right-skewed asymmetry, suggesting a majority of economical drivers who closely follow eco-driving rules (Table 3).

Table 3. Average decrease fuel consumption

\begin{tabular}{|c|c|c|c|c|c|c|c|c|}
\hline \multicolumn{1}{|c|}{ Differences (without and with eco-driving) in fuel consumption in the city } \\
\hline Age & N & average & ME & Min & Max & S & alfa3 & alfa4 \\
\hline Age over 60 & 36 & -0.64 & -0.60 & -3.00 & 4.00 & 1.14 & 1.63 & 7.14 \\
\hline Age $51-60$ & 41 & -0.73 & -0.20 & -10.00 & 0.50 & 1.65 & -4.73 & 26.12 \\
\hline Age $31-40$ & 170 & -0.93 & -1.00 & -9.00 & 3.00 & 1.02 & -3.27 & 25.07 \\
\hline Age 26 - 30 & 74 & -0.77 & -0.70 & -6.87 & 4.00 & 1.34 & -0.97 & 7.22 \\
\hline Age 41-50 & 108 & -0.84 & -1.00 & -3.50 & 1.00 & 0.80 & -0.46 & 0.42 \\
\hline Age up to 25 & 29 & -1.41 & -1.00 & -7.00 & 0.00 & 1.49 & -2.13 & 6.22 \\
\hline
\end{tabular}

Source: Author's own research

From an analysis of the eco-driving awareness factor, it can be seen that there is considerable variety in factor values, which makes mean-based interpretation rather difficult. As in the case of age, however, value distribution should be taken into account. The group which is the most homogenous in terms of dispersion $(\mathrm{V}(\mathrm{S})=101 \%)$ and least 
asymmetrical is represented by those who declare eco-driving awareness and practice (alfa3=-0.22; Table 4).

Table 4. Contribution of eco-driving awareness to fuel consumption savings in city driving

\begin{tabular}{|c|c|c|c|c|c|c|c|c|c|}
\hline $\begin{array}{c}\text { Eco-drive } \\
\text { perception }\end{array}$ & $\mathbf{N}$ & average & $\mathbf{M E}$ & $\mathbf{M i n}$ & $\mathbf{M a x}$ & $\mathbf{S}$ & $\mathbf{V ( S )}$ & $\mathbf{a l f a 3}$ & $\mathbf{a l f a 4}$ \\
\hline $\begin{array}{c}\text { I have never met with } \\
\text { this concept }\end{array}$ & 47 & -0.66 & -0.50 & -6.87 & 4.00 & 1.45 & -217.96 & -1.26 & 8.45 \\
\hline $\begin{array}{c}\text { I have met with this } \\
\text { concept, but I do not } \\
\text { know exactly what it } \\
\text { means }\end{array}$ & 134 & -0.87 & -1.00 & -10.00 & 3.00 & 1.30 & -150.17 & -3.46 & 21.37 \\
\hline $\begin{array}{c}\text { I have met with this } \\
\text { concept, and I know } \\
\text { exactly what it means }\end{array}$ & 271 & -0.88 & -1.00 & -5.00 & 4.00 & 0.89 & -101.18 & -0.22 & 5.38 \\
\hline $\begin{array}{c}\text { I do not know / hard } \\
\text { to say }\end{array}$ & 6 & -2.25 & -1.00 & -9.00 & 0.00 & 3.34 & -148.57 & -2.33 & 5.57 \\
\hline
\end{tabular}

Source: Author's own research

From an analysis of the occupation factor's value distribution, it seems that the best ecodrivers are self-employed respondents. Although the saving on fuel consumption (-0.83) is not the lowest in this group, self-employed respondents exhibit the smallest dispersion and a right-skewed asymmetry, suggesting that a majority of these people apply eco-driving techniques correctly (fuel consumption below average) (Table 5).

Table 5. Contribution of occupation to fuel consumption savings in city driving

\begin{tabular}{|c|c|c|c|c|c|c|c|c|c|}
\hline Occupation & $\mathbf{N}$ & average & ME & Min & Max & S & V(S) & alfa3 & alfa4 \\
\hline pensioner & 28 & 34.57 & -1.01 & -0.50 & -10.00 & 1.95 & -191.96 & -3.88 & 17.78 \\
\hline employee & 296 & 47.90 & -0.88 & -1.00 & -9.00 & 1.16 & -132.12 & -2.15 & 13.73 \\
\hline entrepreneur & 103 & 46.19 & -0.83 & -1.00 & -4.00 & 0.87 & -105.10 & 1.05 & 9.46 \\
\hline unemployed & 31 & 39.74 & -0.81 & -1.00 & -3.00 & 0.93 & -115.08 & -0.75 & 0.48 \\
\hline
\end{tabular}

Source: Author's own research

It remains an open question if, besides ecological considerations, the decisive contributor to eco-driving is the economic motivation (saving money).

\section{Conclusions}

Eco-driving is a technique which contributes to reducing fuel consumption, demand for resources and, as a result, limiting atmosphere degradation thanks to lower carbon dioxide emissions. It also leads to savings on transport costs (e.g. road infrastructure), lower street noise levels and improving living standards as a result of reduced dust content in the air and alleviating the danger of smog.

Poland is seeing more measures being taken in that direction. There are driving schools instructing students in eco-driving techniques. Various educational centres provide courses, training and lessons. Drivers are becoming more aware of and knowledgeable about ecodriving. It is hoped that eco-driving will gain widespread approval as a way of environmental care, a response to the need for savings and for greater social awareness.

The research suggests that the essential factors contributing to eco-driving awareness and practice, and in turn to fuel savings are gender, age and occupation. The models 
confirm the hypotheses and allow a precise quantitative description of the trends under survey.

\section{References}

1. http:// www.who.int /mediacentre /factsheets / fs313/en/, (2008)

2. http://www.eea.europa.eu/data-and-maps/indicators/air-pollution-by-ozone$1 /$ assessment

3. WHO Regional Office for Europe. Copenhagen (2006)

4. World Health Organization. WHO Library Cataloguing-in-Publication Data, (2009)

5. Technical report. WHO, (2013)

6. EEA: Towards clean and smart mobility. Transport and environment in Europe (2016)

7. I. Sówka, Czysta Energia, 1-2 (2017)

8. Tracking Progress Towards Europe's Climate and Energy Targets for 2020, EEA, 45 (2014)

9. M. Lempart, P. Malik, Organizacja i Zarządzanie, Zeszyty Naukowe Politechniki Poznańskiej, 60 (2013)

10. K. Boriboonsomsin, A. Vu, M. Barth, University of California Transportation Center, (2010)

11. R. Andoa, Y. Nishihori, , Procedia Social and Behavioral Sciences 20 (2011)

12. C. Andrieu, G. Saint Pierre, Procedia - Social and Behavioral Sciences 54 (2012)

13. A. Schroten, Domain Report Transport, CE Delft (2012)

14. A. E. Wahlberg, International Journal of Industrial Ergonomics 37 (2007)

15. M. Zarkadoula, G. Zoidis, E. Tritopoulou, Transportation Research Part D 12, (2007)

16. B. Beusen, S. Broekx, T. Denys, C. Beckx, B. Degraeuwe, M. Gijsbers, K. Scheepers, L. Govaerts, R. Torfs, L. L. Panis, Transportation Research Part D 14 (2009)

17. J. N. Barkenbus, Energy Policy 38 (2010)

18. G. Majewski, W. Rogula-Kozłowska, P.O. Czechowski, A. Badyda, A. Brandyk, Atmosphere 6 (2015)

19. W. Rogula-Kozłowska, G. Majewski, P.O. Czechowski, P. Rogula-Kopiec, EPE 43, 1 (2017)

20. A. Badyda, P. Dąbrowiecki, P.O. Czechowski, G. Majewski, Respiratory Physiology \& Neurobiol. 209 (2014) 